\title{
Type 2 Diabetes and Hypertension among Saudi Patients with Obesity
}

\author{
Khalid S Aljabri ${ }^{1 *}$, Samia A Bokhari ${ }^{1}$, Muneera A Alshareef ${ }^{1}$, Patan M Khan ${ }^{1}$ and Bandari K. Aljabri ${ }^{2}$ \\ ${ }^{1}$ Department of Endocrinology, Jeddah, Kingdom of Saudi Arabia \\ ${ }^{2}$ College of medicine, Um Al Qura University, Makkah, Kingdom of Saudi Arabia
}

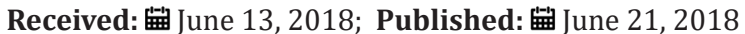

*Corresponding author: Khalid SJ Aljabri, Department of Endocrinology, King Fahad Armed Forces Hospital, Jeddah, Kingdom of Saudi Arabia, PO Box 9862, Jeddah 21159, Kingdom of Saudi Arabia

\section{Abstract}

Background and Objective: Obesity is a major risk factor for non communicable diseases.

Obesity, diabetes and hypertension are so tightly linked. This study aims to determine the frequency of type 2 diabetes and hypertension among obese Saudi population.

Methods: We analyzed participants who are older than 18 years old. A total of 2452 cases with body mass index $\geq 30.0 \mathrm{~kg} / \mathrm{m}^{2}$ were selected to be enrolled for the present study. All patients were from the population of the Primary health and Diabetic Centres at King Fahad Armed Forces Hospital.

Main results: A total of 2452 participants were studied. The mean age of the study population was $45.7 \pm 14.6$ years, $46.9 \pm 15.3$ years for males and $45.1 \pm 14.2$ years for females. Moreover, the prevalence of males was $805(32.8 \%)$ and the prevalence of females was $1647(67.2 \%)$ with males to females ratio was 1.00: 2.01. Mean BMI was 34.9 \pm 4.4 . Type 2 diabetes and hypertension had been diagnosed in $930(37.9 \%)$ and 538(21.9\%) respectively. In the study population, 1502(61.3\%) were obese Grade I, 671 (27.4\%) were obese Grade II while 279 (11.4\%) were morbidly obese (obese Grade III). Moreover, increased body mass index were strongly linked to females, $61.8 \%, 72.7 \%$ and $82.8 \%$ respectively and this was found to be statistically significant $(\mathrm{p}<0.0001)$. Moreover, increased with body mass index categories were strongly linked to females and this was found to be statistically significant $(\mathrm{p}<0.0001)$. There were no significant differences between different with body mass index grades and mean age, frequency of type 2 diabetes and hypertension. The peaks for all mean and body mass index categories were at age 30-34 years and 50-54 years with higher mean and body mass index categories for females. There were nonsignificant associations between obesity and hypertension or diabetes. In regard to the relationship between body mass index categories and type 2 diabetes and hypertension in different age ranges, it was observed that type 2 diabetes, hypertension and type 2 diabetes associated with hypertension are increasing among 45-49 years and 50-54 years age ranges, with female predominance in those age groups.

Conclusion: This study found the frequency of type 2 diabetes and hypertension was not associated differently between different obesity subclasses. Indeed, weight gain associated with aging seems to further constitutes a threat to public health status in developing societies. Clearly, despite the small sample size, this study has posed important public health issues that require immediate attention from the health authority.

Keywords: Type 2 Diabetes, Hypertension and obesity

\section{Introduction}

Obesity is a major risk factor for illness and death [1]. It is defined by a 30 or higher body mass index (BMI) irrespective of whether objectively measured or based on self-report [2]. A BMI of 35 or more with serious comorbidity, or a BMI of 40 or more, is considered morbid obesity. Other definitions of morbid obesity 
include more than $45.2 \mathrm{~kg}$ over the ideal body weight as defined by the 1983 Metropolitan Life Insurance Height and Weight tables or a body weight exceeding $200 \%$ of the ideal body weight. There was a 12-fold excess mortality compared with the general population in the 25- to 34-year-old group and 6-fold excess mortality in the 35- to 44-year-old group. The hallmark study in 1980 clearly demonstrated during the course of the study, $25 \%$ of the group died [3]. At least 2.8 million adults die each year as a result of being overweight or obese. In addition, $44 \%$ of the diabetes burden, $23 \%$ of the ischaemic heart disease burden, and between $7 \%$ and $41 \%$ of certain cancer burdens are attributable to overweight and obesity [4]. Socially, obesity is now perceived as a health problem and a risk factor for many diseases [5]. The Global Burden of Disease 2010 study found that elevated BMI was the leading risk factor for disability-adjusted life years in Saudi Arabia [6].

In 2008, the WHO estimated that at least 500 million adults are obese, over 200 million men and nearly 300 million women were obese [7]. About $11 \%$ of adults aged 20 were obese [5]. The prevalence of obesity was highest in the Americas (26\%) and lowest in South East Asia (3\%) [8]. obesity is increasing in Saudi Arabia, especially in females. The research studies find prevalence of obesity range from $3.8 \%$ to $63.6 \%$ [9-24]. The current trends and future projections of adult obesity prevalence showed that the overall obesity will increase to $41 \%$ in men and $78 \%$ in women by 2022 in Saudi Arabia [20].

Severely obese individuals who are $45-90 \mathrm{~kg}$ or more or BMI $\geq 40.0 \mathrm{~kg} / \mathrm{m}^{2}$ have on average far more complex health issues and encounter very different challenges in the health care system than the majority of moderately obese individuals (BMI 35.0-39.9). Over the last 3 decades, mean BMI has increased by $0.4 \mathrm{~kg} / \mathrm{m} 2$ per decade worldwide [25]. According to recent studies, the United States has the highest mean BMI among high income countries, resulting in 1 in 3 adults having a BMI over 30 based on objective measurement or 1 in 4 adults based on self-reported height and weight [2527]. The prevalence of moderate obesity may be stabilizing or at least increases are occurring at much smaller rates than prior to 2005 in the US [26-28]. This plateauing may or may not apply to more severe/ morbid obesity. Clinically severe or morbid obesity is not a rare pathological condition afflicting a fixed proportion of the population, nor is it directly coupled to the prevalence of moderate obesity. Instead, severe obesity is part of a population BMI distribution that has become more heterogeneous (a larger proportion of individuals far away from the average) while shifting to the right simultaneously (an increase in mean BMI) [26,29].

Obesity and diabetes are so tightly linked that the American Diabetes Association recommends physicians test for type 2 Diabetes and assess risk of future diabetes in asymptomatic people $\geq 45$ years old simply if they are obese, and regardless of age if they are severely obese [30]. Obesity raises risk of developing type 2 Diabetes by a factor of seven, compared to normal weight [31]. While not every obese individual has diabetes, $80 \%$ of those with diabetes are overweight/obese [32]. In Saudis studies, it was shown that the prevalence of obesity was significantly higher in diabetic and hypertensive Saudis compared to the non-diabetic and non-hypertensive controls [33-35]. This study aims to determine the frequency of T2DM and HTN among obese Saudi population.

\section{Methods}

For the present study, we analyzed participants who are older than 18 years old. A total of 2452 cases with BMI $\geq 30.0 \mathrm{~kg} / \mathrm{m}^{2}$ were selected to be enrolled for the present study. All patients were from the population of the Primary health and Diabetic Centers at King Fahad Armed Forces Hospital. Participants were defined as having T2DM according to self-report, clinical reports, use of anti diabetic agents and HbA1c $(\geq 6.5)$ [30]. All data were collected by personal interview and on the basis of a review of electronic medical data. Weight $(\mathrm{kg})$ and height $(\mathrm{cm})$ were measured by physician and nurse interviewers and recorded. Obesity was defined as BMI $\geq 30.0 \mathrm{~kg} /$ $\mathrm{m}^{2}$ [36]. BMI values of $\geq 30.0 \mathrm{~kg} / \mathrm{m}^{2}$ were sub classified into groups as obese Grade I (BMI $\left.=30-34.9 \mathrm{~kg} / \mathrm{m}^{2}\right)$, obese Grade II (BMI=35.0$\left.39.9 \mathrm{~kg} / \mathrm{m}^{2}\right)$ and morbidly obese Grade III $\left(B M I \geq 40 \mathrm{~kg} / \mathrm{m}^{2}\right)$. The total number of subjects were separated on basis of age values into 10 groups; <25 years, 25-29 years, 30-34 years, 35-39 years, 4044 years, $45-49$ years, 50-54 years, 55-59 years , 60-64 years and $\geq 65$ years. Blood Pressure readings were within a gap of 15 minutes using a mercury sphygmomanometer by palpation and auscultation method in right arm in sitting position. Two readings were taken 15 min apart and the average of both the readings was taken for analysis. Hypertension (HTN) was also diagnosed based on anti HTN medications or having a prescription of antihypertensive drugs and were classified as Hypertensive irrespective of their current blood pressure reading or if the blood pressure was greater than 140/90 mmHg i,e systolic BP more than 140 and diastolic BP more than 90 mm of Hg - Report of the American College of Cardiology/American Heart Association Task Force on Clinical Practice Guidelines [37].

\section{Statistical Analysis}

Univariate analysis of demographic and clinical laboratory was accomplished using one-way analysis of variance (ANOVA) with post hoc analysis between variables, to estimate the significance of different between groups where appropriate. Unpaired t-test was used to analyze univariate analysis when appropriate. Chi square $\left(\mathrm{X}^{2}\right)$ test were used for categorical data comparison. The adjusted odds ratio (OR) with a 95\% confidence interval (CI) was calculated. All statistical analyses were performed using SPSS Version 22.0. The difference between groups was considered significant when $\mathrm{P}<0.05$.

\section{Results}

A total of 2452 participants were studied. The mean age of the study population was $45.7 \pm 14.6$ years with $46.9 \pm 15.3$ years for males and $45.1 \pm 14.2$ years for females. Moreover, the prevalence of males was $805(32.8 \%)$ and the prevalence of females was 
$1647(67.2 \%)$ with males to females ratio was 1.00: 2.01 , Table 1. Mean BMI was $34.9 \pm 4.4 \mathrm{~kg} / \mathrm{m}^{2}$. T2DM and HTN had been diagnosed in $930(37.9 \%)$ and $538(21.9 \%)$ respectively. In the study population, 1502(61.3\%) were obese Grade I, 671 (27.4\%) were obese Grade II while 279 (11.4\%) were morbidly obese (obese Grade III). Moreover, increased BMI were strongly linked to females; $61.8 \%, 72.7 \%$ and $82.8 \%$ respectively and were found to be statistically significant $(\mathrm{p}<0.0001)$, as indicated in Table 1 . Moreover, increased BMI categories were strongly linked to females and this was found to be statistically significant $(\mathrm{p}<0.0001)$, as indicated in Table 1 . There were no significant difference between different BMI grades and mean age, frequency of T2DM and HTN.

Table 1: Characteristics of patients according to body mass index $\left(\mathrm{kg} / \mathrm{m}^{2}\right)$.

\begin{tabular}{|c|c|c|c|c|c|c|}
\hline \multirow{2}{*}{\multicolumn{2}{|c|}{ Parameters }} & \multirow{2}{*}{ Total } & \multicolumn{3}{|c|}{ Body mass index $\left(\mathrm{kg} / \mathrm{m}^{2}\right)$} & \multirow{2}{*}{$P$ value } \\
\hline & & & $30.0-34.9$ & $35.0-39.9$ & $\geq 40.0$ & \\
\hline \multicolumn{2}{|c|}{ Number (\%) } & 2452 & $1502(61.3)$ & $671(27.4)$ & $279(11.4)$ & \\
\hline \multicolumn{2}{|c|}{ Age (years) } & $45.7 \pm 14.6$ & $45.8 \pm 14.7$ & $45.9 \pm 14.5$ & $44.9 \pm 14.6$ & 0.6 \\
\hline \multirow{2}{*}{ Gender } & Male & $805(32.8)$ & $574(38.2)$ & $183(27.3)$ & $48(17.2)$ & $<0.0001$ \\
\hline & Female & $1647(67.2)$ & $928(61.8)$ & $488(72.7)$ & $231(82.8)$ & \\
\hline \multicolumn{2}{|c|}{ Body mass index $\left(\mathrm{kg} / \mathrm{m}^{2}\right)$} & $34.9 \pm 4.4$ & $32.2 \pm 1.4$ & $37.1 \pm 1.4$ & $44.1 \pm 4.3$ & $<0.0001$ \\
\hline \multicolumn{2}{|c|}{ Type 2 diabetes } & $930(37.9)$ & $562(37.4)$ & $258(38.5)$ & $110(39.4)$ & 0.8 \\
\hline \multicolumn{2}{|c|}{ Hypertension } & $538(21.9)$ & 311 (20.7) & $155(23.1)$ & $72(25.8)$ & 0.1 \\
\hline
\end{tabular}

Data are means \pm SD or number $(\%)$
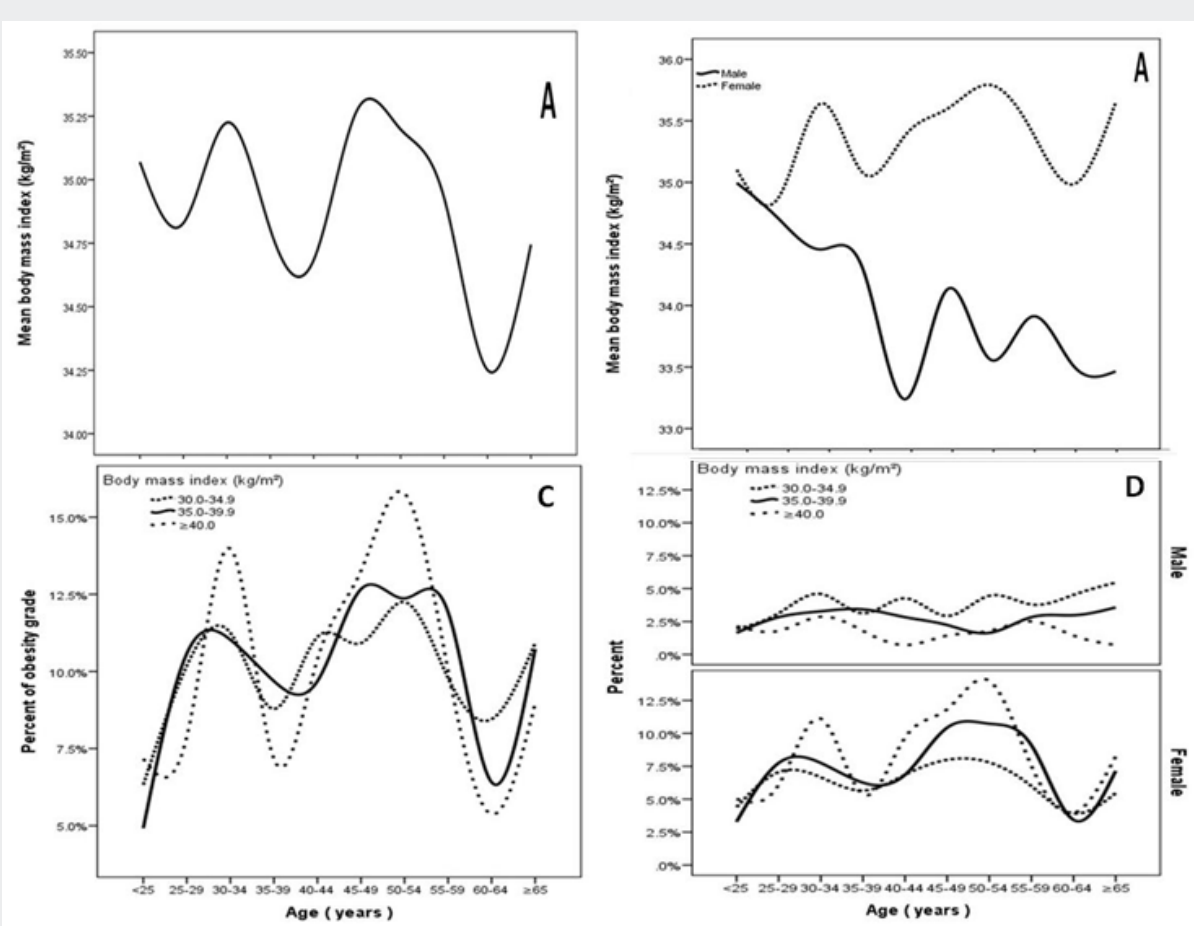

Figure 1: A-D, Description mean and body mass index category by different age ranges and according to gender.

Figure 1 summarizes the relationship between obesity and different age groups. The peaks for all mean and BMI categories were at age 30-34 years and 50-54 years, as indicated in Figure 1, $\mathrm{A}$ and $\mathrm{C}$ with higher mean and BMI categories for females, Figure $1, \mathrm{~B}$ and D. There was no significant association between obesity and hypertension or diabetes. In regard to the relationship between BMI categories and T2DM or HTN in different age ranges, it was observed that T2DM, HTN and T2DM associated with HTN are increasing among 45-49 years and 50-54 years age ranges, with female predominance in those age groups, Figure 2, A-F. 

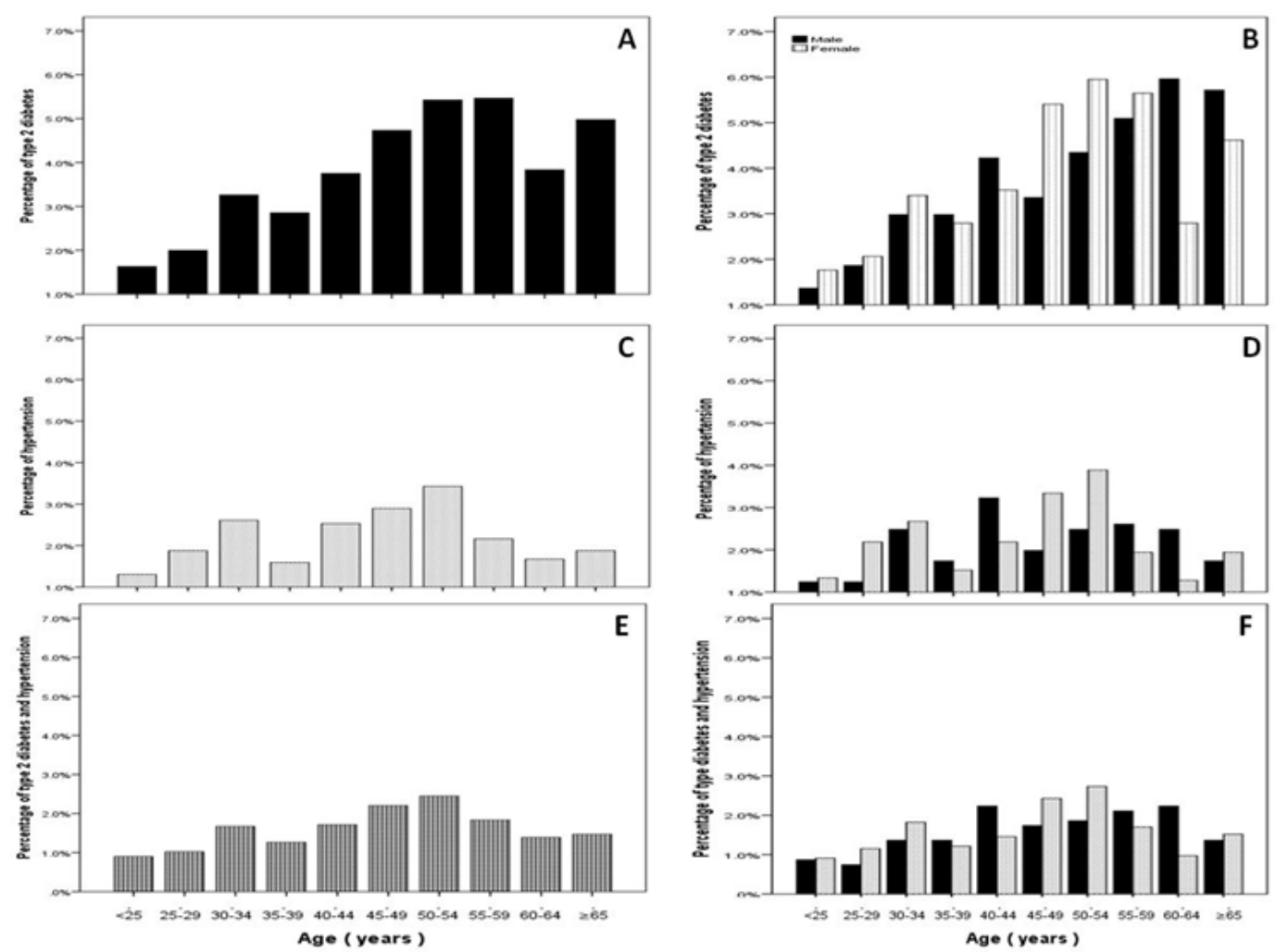

Figure 2: A-F, Description type 2 diabetes, hypertension and diabetes associated with hypertension by different age ranges.

\section{Discussion}

The Global Burden of Disease 2010 study found that elevated BMI was the leading risk factor for disability-adjusted life years in the Kingdom of Saudi Arabia [38]. Previous studies in Saudi Arabia indicate an increasing trend in the prevalence of obesity. Data from the late 1980s through mid-1990s show a prevalence of obesity averaging about $20 \%$ ranging from as low as $13.1 \%$ among men to as high as $26.6 \%$ among women. However, all prevalence estimates from 1995 and beyond are above 35\% [10,13,24,33].

Our study showed the peaks for all mean and BMI categories were at age 30-34 years and 50-54 years, as indicated in Figure 1, $A$ and $C$ with significant higher mean BMI ( $34.0 \pm 3.7$ vs. $35.4 \pm 4.6$, $\mathrm{p}<0.0001$ ) and BMI categories for females in concordance with other reports [38-41]. The Asia Pacific Cohort Studies Collaboration reports obesity prevalence rates ranging from less than $1 \%$ to higher than 20\% for countries in the Asia-Pacific region [42]. According to National Health and Nutrition Examination Survey of the United States, the prevalence of obesity in individuals aged 20-74 years was $34 \%$ in females and $31.7 \%$ in males [43]. The corresponding figures in Australia were $19 \%$ and $17 \%$, respectively [44]. In the United Kingdom, the prevalence of obesity was estimated to be $24.2 \%$ in females and $23.7 \%$ in males [45]. The results from most of our neighbouring countries, including Oman, $23.8 \%$ in females and $16.7 \%$ in males [46]. Lebanon, $18.8 \%$ in females and $14.3 \%$ in males [47]. Turkey as well, the prevalence of obesity is higher in females $24.6 \%$ vs. $14.4 \%$ in males and Iran, the prevalence of obesity to be
$22.3 \%$ among Iranian adults $30.6 \%$ in females and $14.2 \%$ in males $[48,49]$. In Saudi Arabia, the National Epidemiological Household survey among Saudi subjects over the age of 15 years in different regions of Saudi Arabia showed the prevalence of overweight among male subjects was significantly higher than for female subjects (29\% vs. 27\%), and the prevalence of obesity among female subjects was significantly higher than for male subjects (24\% vs. $16 \%$ ) [23].

In Saudi Arabia A community-based national epidemiological health survey, conducted by examining Saudi subjects in the age group of 30-70 years of selected households over a 5-year period between 1995 and 2000 showed that the rate of obesity among adults remained steady at $22.1 \%$ (males $17.8 \%$ and females $26.6 \%$ ) in 1990 and 1993 and increased thereafter to $35.6 \%$ (females $44 \%$ and males 26.4) in 1995 and 2000. This trend can also be seen in overweight Saudis as the percentage of overweight adults in the Saudi Arabia increased from 31.2\% (33.1\% males and 29.4\% for females) to $36.9 \%$ ( $42.4 \%$ of males and $31.8 \%$ of females) in the same time period [13]. The multiple logistic regression analysis showed that age and gender are statistically significant predictors of obesity. The observed prevalence and pattern of overweight and obesity with age and gender is similar to those observed in the Arab community and some Western nations.

In a cross-sectional study in the Gassim region of Saudi Arabia, 6,044 subjects $(2,727$ males and 3,317 females) had their BMI computed in the following age groups, namely, 0-5, 6-12, 13-49, 50- 
69 and 70+ years. In general, the trend for BMI was to increase with age in both genders, but the curve pattern showed some plateauing from about the age of 50, with a slight decline in later life. Females had significantly higher indices than males [50]. Recent study showed the prevalence of obesity was $40.3 \%$ where $62.0 \%$ of the total female population was obese compared to $49.7 \%$ of the total male population. The magnitude of the difference in prevalence of obesity in the males and females was significantly high $(\mathrm{p}<0.0001)$ [51]. With the increase in life expectancy, obesity is causing more years of disability [52]. Hence, the increased cost of obesity and its sequelae will put a strain on the resources of governments and individuals [53].

There is apparently gradual weight gain with age, which tends to decrease gradually after the age of 55 years. The decline in mean BMI in the oldest age group was consistent with other studies [5457]. The increase in obesity levels with age is of concern, as it has been shown that obese elderly are more likely to present with major chronic health conditions and poor general health [58].

The association we found between obesity and chronic non communicable diseases among Saudis is informative on the impact of obesity on chronic diseases in Saudi Arabia. Different studies have documented that more than $80 \%$ of T2DM are obese, and adult males are more likely to be obese than females [59-60]. In Arab societies, it has been found that the high prevalence of Noninsulin dependent diabetes mellitus (NIDDM) is associated with high prevalence of obesity [61]. In Bahrainis, the high rate of diabetes is associated with obesity, but not with overweight [62]. We report high frequency of T2DM, 32.8\% of the male, and $67.2 \%$ of the female, $\mathrm{p}<0.0001$. In a study from KSA to assess the effect of obesity on diabetes and hypertension, the prevalence of obesity among T2DM and HTN patients was $46 \%$ and 54\% respectively which are lower than our report [63].

Frequency of T2DM, HTN or both was not associated with different categories of obesity in our study in disconcordance to others [64-65]. With the inclining rates of obesity over the last 8 years in Saudi Arabia, we would expect an effect on these conditions in our community. The global obesity epidemic has been strongly linked with these diseases [66]. In 2010, hypertension was the second leading risk for death worldwide, and diabetes caused more than 1,200,000 deaths, compared with fewer than 600,000 in 1990. 66 Hypertension and diabetes are contributing extensively to these unhealthy years lived with disability, increasing health expenditures and reducing quality of life. Although we focused in our study on obesity as an extreme measure of excess weight, overweight should also be a target for prevention. Intervening with overweight Saudis before reaching the obesity level would be easier and more beneficial, especially if they have not yet developed adverse health events.

Our study has some limitations. First, our data are retrospective, so we cannot assess causality in associations. Conversely, our study is based on a large sample size and used standardized methods for all its measures. The results of this study have three important implications for national obesity management programs. First, it appears that obesity prevalence rates will almost certainly continue to rise in the Saudi population over the next decade. The rapid aging of the currently very young Saudi population into highrisk older age-groups will maintain the spread between incidence and morbidity into the foreseeable future. Even if incidence rates were flat or declining due to a breakthrough in obesity prevention, prevalence rates would continue to rise. As a result, the health burden due to all types of obesity complications will likely continue. This means that the health care and social service systems should start preparing now to provide the prevention and support services and systems, a large number of adults with obesity are going to require maintaining quality of life.

These include healthy life programs which are currently implemented in our institution, dietary counselling services, and enhanced infrastructure at the community level to facilitate independent living by adults with limited mobility and eyesight. Second, "upstream" population-based primary prevention programs need to be aggressively implemented to ensure that obesity incidence begins to decrease in the future. The dramatically higher rates of obesity in the Saudi population highlight the urgency of this activity. Because obesity appears to be closely related to the adoption by people of many aspects of the modern lifestyle including diet and low levels of physical activity, prevention programs that draw upon Aboriginal traditions and ways of life and that focus on the lifestyle habits of Aboriginal youth need to be implemented. A number of very promising primary prevention programs that draw upon Aboriginal traditions and ways of life have been implemented in our institution. Third, the reason for the higher prevalence of obesity in Saudi women observed in this study also needs to be better understood.

\section{Conclusion}

This study found the frequency of T2DM and HTN were not associated differently between different obesity subclasses. Indeed, weight gain associated with aging seems to further constitutes a threat to public health status in developing societies. Clearly, despite the small sample size, this study has posed important public health issues that require immediate attention from the health authority.

\section{Acknowledgment}

We are grateful to the staffs from the diabetic centre at King Fahad Armed Forces Hospital for their valuable contributions in data collection. The authors have no conflict of interest to disclose.

a) Stimulating the glucose uptake in L6 myotubes $[13,14]$

b) Inhibiting adipocyte differentiation [14]

c) Improving glucose homeostasis and symptoms in animal model of gestational diabetes [15] 
d) Promoting formation of brown adipocytes and exerting thermogenic effects [16]

With this editorial, we would like to propose a start point for discussion and an input for further investigations about the role of RSV-based nutraceuticals, which have been shown to be not a mere palliative but a novel and promising natural approach for the management of diabesity. We hope this Journal will encourage the scientific discussion regarding the role of nutraceutical sciences in metabolic diseases focusing on the evidences, safety and absence of side-effects, enlarging the knowledge of physician on this issue.

\section{References}

1. Haslam DW, James WP (2005) Obesity. Lancet 366(9492): 1197-1209.

2. Twells LK, Gregory DM, Reddigan J, Midodzi WK (2004) Current and predicted prevalence of obesity in Canada: a trend analysis. CMAJ 2(1): e18-e26.

3. Drenick EJ, Bale GS, Seltzer FS, Johnson DG (1980) Excessive mortality and causes of death in morbidly obese men. JAMA 243(5): 443-445

4. WHO Media Centre (2013) Obesity and Overweight, World Health Organization, Geneva, Switzerland.

5. Nocito A, Balke H (2013) A trip through the history of obesity. Praxis [Berne 1994] 102(2): 77-83.

6. Institute for Health Metrics and Evaluation (2013) GBD Compare: cause of disease or injury, Saudi Arabia, stacked bar chart. Seattle (WA): University of Washington.

7. WHO (2009) Obesity and Overweight, World Health Organization.

8. Global Health Observatory (GHO) (2013) Obesity: Situation and Trends, World.

9. Sabra AA (2014) Obesity among female intermediate nursing students of health science collage in Dammam city, Saudi Arabia: prevalence and associated factors. Canadian Journal of Clinical Nutrition 2(1): 29-45.

10. Memish ZA, El Bcheraoui C, Tuffaha M, Robinson M, Daoud F, et al. (2014) Peer Reviewed: Obesity and Associated Factors-Kingdom of Saudi Arabia. Preventing Chronic Disease 11: E174.

11. El Nashar DE, Alananbeh KM, Al Hassan N (2016) Genetic, dietary, and non-dietary risk factors of obesity among preparatory-year female students at Taibah University, Saudi Arabia. Journal of Taibah University for Science 11(3): 408-421.

12. Horaib GB, Al Khashan HI, Mishriky AM, Selim MA, Al Nowaiser N, et al. (2013) Prevalence of obesity among military personnel in Saudi Arabia and associated risk factors. Saudi medical journal 34(4): 401-407.

13. Al Nozha MM, Al Mazrou YY, Al Maatouq MA, Arafah MR, Khalil MZ, et al. (2005) Obesity in Saudi Arabia. Saudi medical journal 26(5): 824-829.

14. Ahmed HG, Ginawi IA, Elasbali AM, Ashankyty IM, Al-hazimi AM (2014) Prevalence of obesity in Hail region, KSA: in a comprehensive survey. Journal of obesity pp. 289-296.

15. Al Hazzaa HM, Abahussain NA, Al Sobayel HI, Qahwaji DM, Musaiger AO (2012) Lifestyle factors associated with overweight and obesity among Saudi adolescents. BMC Public Health 12: 354

16. Al Hazzaa HM, Abahussain NA, Al Sobayel HI, Qahwaji DM, Alsulaiman NA, et al. (2014) Prevalence of overweight, obesity, and abdominal obesity among urban Saudi adolescents: gender and regional variations. Journal of health, population, and nutrition 32(4): 634-645.

17. Al Mohaimeed A, Ahmed S, Dandash K, Ismail MS, Saquib N (2015) Concordance of obesity classification between body mass index and percent body fat among school children in Saudi Arabia. BMC pediatrics 15: 16.

18. Elbadawi AS, Altemani AH, Alhawiti IS, Altuwaylie MM (2015) Prevalence and risk factors of obesity among male primary school students in Tabuk, Saudi Arabia.

19. Al Shehri A, Al Fattani A, Al Alwan I (2013) Obesity among Saudi children. Saudi Journal of Obesity 1(1): 3-9.

20. Al Quwaidhi AJ, Pearce MS, Critchley JA, Sobngwi E, O Flaherty M (2014) Trends and future projections of the prevalence of adult obesity in Saudi Arabia 1992-2022. Eastern Mediterranean Health Journal 20(10): 589595.

21. Baig M, Gazzaz ZJ, Gari MA, Al Attallah HG, Al Jedaani KS, et al (2015) Prevalence of obesity and hypertension among University students' and their knowledge and attitude towards risk factors of Cardiovascular Disease (CVD) in Jeddah, Saudi Arabia. Pakistan journal of medical sciences 31(4): 816-820.

22. Alzahrani AA, Al Khaldi YM, Alsamghan AS (2016) Prevalence of obesity among Saudi board residents in Aseer Region, Saudi Arabia. Saudi Journal of Obesity 4(1): 13-19.

23. Al Nuaim AR, Al Rabeaan K, Al Mazrou Y, Al Attas O, Al Daghari N, et al (1996) High prevalence of overweight and obesity in Saudi Arabia. International Journal of obesity 20(6): 547-552.

24. Al Othaimeen AI, Al Nozha M, Osman AK (2007) Obesity: an emerging problem in Saudi Arabia. Analysis of data from the National Nutrition Survey. East Medditerr Health Journal 13(2): 441-448.

25. Finucane MM, Stevens GA, Cowan MJ, et al. (2011) National, regional, and global trends in body-mass index since 1980: systematic analysis of health examination surveys and epidemiological studies with 960 country-years and 9.1 million participants. Lancet 377(9765): 557-567.

26. Flegal KM, Carroll MD, Kit BK, Ogden CL (2012) Prevalence of obesity and trends in the distribution of body mass index among US adults, 1999-2010. JAMA 307(5): 491-497.

27. Centers for Disease Control and Prevention (CDC) (2010) Vital signs: state-specific obesity prevalence among adult - United States, 2009. MMWR Morb Mortal Wkly Rep 59(30):951-955.

28. Yanovski SZ, Yanovski JA (2011) Obesity prevalence in the United States-up, down, or sideways? N Engl J Med 364(11): 987-989.

29. Sturm R, Bao Y (2007) Socioeconomics of obesity. In Kushner RF, Bessesen DH, Treatment of the Obese Patient. Humana Press pp. 174194.

30. American Diabetes Association (2018) Classification and Diagnosis of Diabetes: Standards of Medical Care in Diabetes-2018. Diabetes Care 41(Suppl 1): S13-S27.

31. Abdullah A, Peeters A, de Courten M, Stoelwinder J (2010) The magnitude of association between overweight and obesity and the risk of diabetes: A meta-analysis of prospective cohort studies. Diabetes Res Clin Pract 89(3): 309-319.

32. National Diabetes Information Clearinghouse (2014) US Department of Health and Human Services. Diabetes Fact Sheet.

33. Warsy A, El Hazmi M (1999) Diabetes mellitus, hyper-tension and Obesity-common multifactorial dis-orders in Saudis. Eastern Mediterranean Health Journal 5(6): 1236-1242.

34. Al-Turki Y (2000) The prevalence of overweight and obesity amongst hypertensive and diabetic adult patients in primary health care. Saudi Medical Journal 21(4): 340-343.

35. El-Hazmi MA, Warsy AS (2000) Prevalence of overweight and obesity in diabetic and non-diabetic Saudis. Eastern Mediterranean Health 6(2-3): $276-282$. 
36. World Health Organization (1999) Obesity: preventing and managing the global epidemic: report of a WHO consultation. Geneva, Switzerland.

37. Paul K Whelton, Robert M Carey, Wilbert S Aronow, Donald E Casey, Karen J Collins, et al (2018) 2017 ACC/AHA/AAPA/ABC/ACPM/AGS/ APhA/ASH/ASPC/NMA/PCNA Guideline for the Prevention, Detection, Evaluation, and Management of High Blood Pressure in Adults: A Report of the American College of Cardiology/American Heart Association Task Force on Clinical Practice Guidelines. J Am Coll Cardiol 71(6): 12691324.

38. Global Health Observatory (GHO) (2013) Obesity: Situation and Trends, World.

39. MA Faris, S Epuru, D Abu Jamous, M Smadi, A Eideh, et al. (2014) Assessing obesity, body fatness and dietary behaviors among adult college students in Hail, Saudi Arabia. International Journal of Nutrition and Food Sciences 3(2): 60-68.

40. AR Al Nuaim, K Al Rubeaan, Y Al Mazrou, O Al Attas, N Al Daghari, et al. (1996) High prevalence of overweight and obesity in Saudi Arabia. International Journal of Obesity and Related Metabolic Disorders 20(6): 547-552.

41. M Badran and I Laher (2011) Obesity inArabic-speaking countries. Journal of Obesity 2011: 686430.

42. Asia Pacific Cohort Studies Collaboration (2007) The burden of overweight and obesity in the Asia-Pacific region. Obes Rev 8(3): 191196.

43. Ogden CL, Yanovski SZ, Carroll MD, Flegal KM (2007) The epidemiology of obesity. Gastroenterology 132(6): 2087-2102

44. Australian Institute of Health and Welfare (2006) Australia's Health: the tenth biennial health report of Australian Institute of Health and Welfare.

45. The NHS Information Center (2006) Health Survey for England, Latest Trends.

46. Al Lawati JA, Jousilahti PJ (2004) Prevalence and 10-year secular trend of obesity in Oman. Saudi Med J 25(3): 346-351.

47. Sibai AM, Hwalla N, Adra N, Rahal B (2003) Prevalence and covariates of obesity in Lebanon: findings from the first epidemiological study. Obes Res 11(11): 1353-1361.

48. Yumuk VD (2005) Prevalence of obesity in Turkey. Obes Rev 6(1):9-10.

49. Esteghamati A, Meysamie A, Khalilzadeh O, Rashidi A, Haghazali M (2009) Third national surveillance of risk factors of non-communicable diseases (SuRFNCD-2007) in Iran: methods and results on prevalence of diabetes, hypertension, obesity, central obesity, and dyslipidemia. BMC Public Health 9: 167.

50. Soyannwo MA, Kurashi NY, Gadallah M (1998) Body mass index (BMI) in the Saudi population of Gassim. Afr J Med Sci 27(1-2): 117-121.
51. KS Aljabri, K Alqurashi, S Bokhari (2014) High Prevalence of Obesity in Saudi Community. A cross section single centre study. Journal of obesity management 1(1): 1-9.

52. Kelsey MM, Zaepfel A, Bjornstad P, Nadeau KJ (2014) Age-related consequences of childhood obesity. Gerontology 60(3): 222-228.

53. Withrow D, Alter DA (2011) The economic burden of obesity worldwide: a systematic review of the direct costs of obesity. Obes Rev 12(2): 131141

54. Reeder BA, Chen Y, Macdonald SM, Angel A, Sweet L (1997) Regional and rural-urban differences in obesity in Canada. Canadian Heart Health Surveys Research Group. Can Med Ass J 157(Suppl 1): S10-S16.

55. Fitness and lifestyle in Canada (1983) A report by Canada Fitness Survey. Ottawa (CA): Fitness and Amateur Sport Canada.

56. Health and Welfare Canada (1987) The active Health Report: perspectives on Canada health Promotion Survey 1985. Ottawa (CA): Minister of Supply and Services.

57. Asya A Al Riyami, Mustafa M Afifi (2003) Prevalence and correlates of obesity and central obesity among Omani adults. Saudi Medical Journal 24(6): 641-646.

58. Andreyeva T, Michaud PC, van Soest A (2007) Obesity and health in Europeans aged 50 years and older. Public Health 121(7): 497-509.

59. Rudy DR, Tzagourins M (1990) Endocrinology. In Rakel RE, Textbook of Family Practice. 4thedition. USA; WB Saunders Company 1990:1082-7.

60. Hillier TA, Pedula KL (2001) Characteristics of an Adult Population with newly Diagnosed Type 2 Diabetes. Diabetes Care 24(9): 1422-1527.

61. AL Mahroos F (2000) Diabetes Mellitus. In: The Arabian Peninsula. Annals of Saudi Medicine 20(2): 111-112.

62. Al Mahroos F, AL Roomi K (2001) Obesity among Adult Bahraini Population: Impact of Physical Activity and educational level. Annals of Saudi Medicine 21(3-4): 183-187.

63. AM AL Shahrani and YM Al Khaldi (2013) Obesity among diabetic and hypertensive patients in Aseer region, Saudi Arabia. Saudi Journal of Obesity 1(1): 14-17.

64. MN Stagnitti (2009) Trends in Health Care Expenditures by Body Mass Index (BMI) Category for Adults in the U.S. Civilian Non institutionalized Population, 2001 and 2006. Statistical Brief 247: 1-7.

65. MT Zanella, O Kohlmann Jr, and AB Ribeiro (2001) Obesity-and diabetesrelated hypertension: treatment of obesity hypertension and diabetes syndrome. Hypertension 38(3 Pt 2): 705-708.

66. Lozano R, Naghavi M, Foreman K, Lim S, Shibuya K, et al. (2012) Global and regional mortality from 235 causes of death for 20 age groups in 1990 and 2010: a systematic analysis for the Global Burden of Disease Study 2010. Lancet 380(9859): 2095-2128.

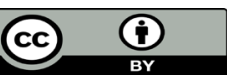

This work is licensed under Creative Commons Attribution 4.0 License

To Submit Your Article Click Here:

Submit Artic

DOI: $10.32474 / A D 0.2018 .01 .000110$

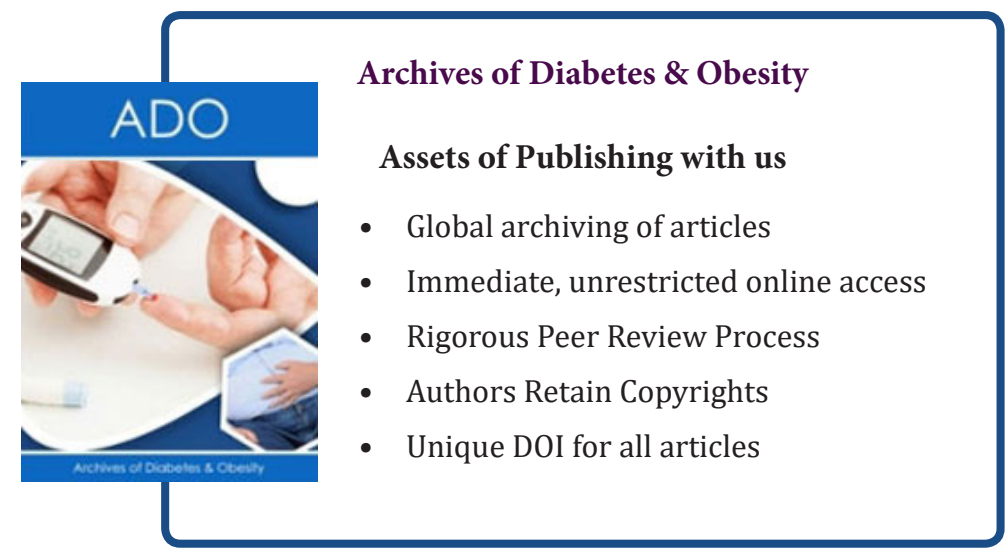

